www.jmscr.igmpublication.org

Impact Factor (SJIF): 6.379

Index Copernicus Value: 71.58

ISSN (e)-2347-176x ISSN (p) 2455-0450

crossref DOI: https://dx.doi.org/10.18535/jmscr/v6i4.193

Journal Of Medical Science And Clinical Research

\title{
Comparison of Clonidine and Dexmedetomidine as an Adjuvant to $0.375 \%$ of Ropivacaine in Supraclavicular Brachial Plexus Block: A Prospective Study
}

\author{
Authors \\ Kamlesh K Shekhawat ${ }^{1}$, Neena Jain ${ }^{2}$, Amit Kumar ${ }^{3}$ \\ ${ }^{1}$ Assistant Professor, Department of Anesthesia, Critical Care and Pain, Pacific Institute of Medical \\ Sciences, Udaipur, Rajasthan, India \\ ${ }^{2}$ Professor and Head, Department of Anesthesia, Critical Care and Pain, JLN Medical College, Ajmer, \\ Rajasthan, India \\ ${ }^{3}$ Senior Resident, Department of Anesthesia, Critical Care and Pain, Pacific Institute of Medical Sciences, \\ Udaipur, Rajasthan, India \\ Corresponding Author
}

Dr Kamlesh K Shekhawat

Assistant Professor, Department of Anesthesia, Critical Care and Pain, Pacific Institute of Medical Sciences, Ambua Road, Village Umarda, Girwa, Udaipur-313015, Rajasthan, India

Email:dr.k.shekhawat15@gmail.com

\begin{abstract}
Background and Objective: Various adjuvants are added to local anesthetic to prolong the duration and faster the onset time of sensory and motor block and increase the quality of various types of peripheral nerve blocks and in local infiltration also. Presented study was conducted in upper limb surgery to evaluate and compare the effect of addition of clonidine and dexmedetomidine in ropivacaine as an adjuvant.

Methodology: This prospective observational study was planned insixty ASA Grade I and II patients scheduled for upper limb surgeries under supraclavicular brachial plexus block and were randomly divided in to two equal groups, 30 patients in each. Group $R C(n=30)$ received clonidine $1 \mathrm{ug} / \mathrm{kg}(1 \mathrm{ml})$ and Group $R D(n=30)$ received dexmedetomidine $1 \mathrm{ug} / \mathrm{kg}(1 \mathrm{ml})$ added to ropivacaine $0.375 \%(39 \mathrm{ml})$, total $40 \mathrm{ml}$ volume was prepared and injected by using paresthesia with blind technique of supraclavicular block. Thereafter, onset time of sensory, motor block, duration of sensory, motor block, duration of analgesia, sedation score, grade of bleeding during surgery, systemic side effects and variation in hemodynamic parameters at different time intervals were studies in both the group.

Results: The duration of sensory and motor block and duration of analgesia was significantly prolonged in $R D$ group as compare to RC group ( $p$ value 0.001) but there was no statistically significant difference in onset of sensory and motor block between two groups and sedation score was better in RD group as compare to RC group.

Conclusion: Dexmedetomidine is better adjuvant compare to clonidine added to ropivacaine $0.375 \%$ in supraclavicular brachial plexus block enhanced the duration analgesia, sensory and motor block and also quality of anesthesia.
\end{abstract}

Keywords: Supraclavicular block, Dexmedetomidine, Clonidine, Ropivacaine. 


\section{Introduction}

Upper limb surgery can be performed in general anesthesia (GA) and also in regional anesthesia (RA). Now a day's RA are gaining a wide popularity in anesthesia clinical practice or as a powerful complement to GA with extra benefit in less cost, less systemic side effects, short hospital stay with fast recovery and extended postoperative pain relief. Surgeon is fully satisfied with GA in view of complete relaxation of patients with minimum interruption in surgical fields. There are various study on RA to find out proper technique to perform RA with minimum procedure related complications and local anesthetic agent with less systemic side effect, and a suitable adjuvant to improve quality of RA to obtain satisfactory surgical conditions like GA. Brachial plexus block is a safe RA for upper limb surgery. Upper extremity blocks may be divided in to the following ${ }^{[1]}$

1. Interscalene block-for shoulder surgery

2. Supraclvicular block-the entire arm

3. Infraclvicular- elbow, below elbow

4. Axillary plexus-below the elbow

Interscalene block is well established for intraoperative and post-operative pain management in shoulder surgery (SX). Axillary approach is easy to perform for brachial plexus block with safety, reliability to provide anesthesia for form arm and hand surgeries. ${ }^{[2,3]}$ But it is difficult in patients with limited movement of shoulder, arm and painful injuries ${ }^{[4]}$.

Supraclavicular block is also safe RA for arm SX. Complications associated upper extremities blocks include nerve damage, intravascular injection, diaphragm dysfunction and pneumothorax, horners syndrome, these complications can be reduced with use of ultrasound guided block. Supraclavicular brachial plexus block is ideal peripheral nerve block (PNB) for upper limb surgery with adequate muscle relaxation, and with good intra operative intraoperative and postoperative analgesia. Local anesthetic agents are categorized in to three group, short, intermediate and longer acting, have been used in PNB. Now a day's commonly used local anesthetic agents are lignocaine and bupivacaine, ropivacaine, levobupivacaine. We choose local anesthetic agents on basis of onset of action, duration of action, and with minimum systemic side effects and better hemodynamic stability. Lignocaine, bupivacaine and ropivacaine, levobupivacaine all are amide derivatives, associated with CNS and Cardiovascular complications, bupivacaine is most cardiotoxic than other amide derivatives. Lignocaine has faster on set of action as compare to bupivacaine and ropivacaine but duration of analgesia is more with bupivacaine and ropivacaine. So we choose ropivacaine as a local anesthetic agents in our study because it is less cardiotoxic and with equal duration of analgesia as bupivacaine. ${ }^{[5]}$ Greater degree of sensory and motor differentiation was noted with ropivacaine as compare to bupivacaine because of it is less lipophilic so less penetration in large myelinated motorfibers ${ }^{[6]}$. Clonidine and dexmedetomidine both are $\alpha_{2}$ receptor agonist, an imidazoline and imidazole derivative respectively, clonidine use as centrally acting anti-hypertensive agent also. Dexmedetomidine is 8 times more selective $\alpha_{2}$ adrenoreceptor agonist as compared to clonidine. It is found to be safe and effective in various neuraxial and regional anesthetic in human ${ }^{[7,8]}$. The aim of present study was to evaluate and compare the effect of clonidine hydrochloride and dexmedetomidine hydrochloride as an adjuvant of ropivacaine hydrochloride in supraclavicular brachial plexus block in view of onset of action, duration of anesthesia, analgesia and motor blockade, sedation score, and grade of surgical bleeding in both the group.

\section{Methods and Materials}

After Ethical Committee approval and obtaining written informed consent this prospective randomized, double-blind clinical study was carried out in JLN Medical College, Ajmer, Rajasthan. Daily average $40-50$ patients attend orthopedic OPD out of them average 5 patient are for (IPD) in patient department with c/o fracture 
arm, forearm, elbow, wrist. We include elective as well as emergency hemodynamically stable, sixty patients of American society of anesthesiology (ASA) physical grade I, II of either sex, age group 18-60 years, who fulfilled the eligibility criteria were included in the study. Patients with history of cardiac, respiratory, renal and hepatic disorders, pregnant women, neurological disorders and patients known to sensitive or allergic to study drugs and those patients also exclude from the study in whom brachial plexus block is contraindicated such as coagulopathy disorder, local infection and patient refusal. Patients were subsequently randomized into two groups of 30 each.

Group RC: Ropivacaine hydrochloride $0.375 \%$ $(39 \mathrm{ml})+$ clonidine $1 \mu \mathrm{g} / \mathrm{kg}(1 \mathrm{ml})=40 \mathrm{ml}$

Group RD:Ropivacaine hydrochloride $0.375 \%$ $(39 \mathrm{ml})+$ dexmedetomidine $1 \mu \mathrm{g} / \mathrm{kg}(1 \mathrm{ml})=40 \mathrm{ml}$

Drugs was prepared by investigator anesthesiologist and attending anesthesiologist and patients was unware about injectable drugs. All patients who participate in study kept nil by mouth (NBM) for 8 hour before surgery and tablet alprazolam $0.25 \mathrm{mg}$ was given at bed time day before surgery and in morning tablet ranitidine $150 \mathrm{mg}$ with sips of water given $45 \mathrm{~min}$ before shifting the patients to operation theater (OT) and thereafter shift to preoperative ward where all the baseline vital parameters including blood pressure, pulse rate, SPO2 was recorded than shift to OT, taken on OT table, than $18 \mathrm{G}$ IV cannula was secured on nonoperating hand, ringer lactate solution was started at the rate of $80 \mathrm{ml} /$ hour and NIBP, Pulse oximeter, ECG monitors were attached and basal readings were recorded. Before performing block in operating hand procedure explained to patients and injection midazolam $2 \mathrm{mg}$ IV given to patients as a anxiolytic agent and ondansetron as antiemetic. Than after patient placed in supine position with the head turned about 30 degree to contral ateral side after placing a folded sheet below the shoulder and the arms were extended and pulled towards the knee. Blind technique used to perform block on the basis of external anatomical landmark. The midclavicular point, external jugular vein and subclavian artery pulsation were identified and the area of performing block was painted with $2 \%$ chlorhexidine than draped under sterile hole towel. Thereafter we put our three fingers on subclavian artery pulsation and study drug injected after negative aspiration of blood using $20 \mathrm{ml}$ syringe, $18 \mathrm{G}$, $1.5 \mathrm{inch}$ long needle, $2 \mathrm{~cm}$ above the mid-clavicular point directed just lateral to subclavian artery pulsation caudal and medially until paresthesia was elicited. Immediately after the injection of drugs, patients were asked about the pain relief and to move the forearm at elbow joint to assess the sensory and motor block respectively. The objective assessment was made by pinprick and flexion and extension at elbow joint. Pin prick method was used to assess sensory block and grade was given to every patient according to score, we used three grade to evaluate sensory block, the grade was $0,1,2$. The 0 grade for sharp pain, 1 for only touch sensations and 2 for loss of touch sensation also. Motor block was assessed by use of scale proposed by by Bromage PR, 1978) ${ }^{[9]}$ and according to this scale 3 grade was given to patents, these were 0,1 and 2.0 fornormal motor function with full flexion and extension of elbow, wrist and fingers, 1 for decreased motor strength with ability to move fingers only, 2 for complete motor block with inability to move fingers. Upper limb motor block was also assessed by function of individual nerve function like radial, ulnar, median and musculocutaneous nerves so after injecting study drugs thumb abduction, adduction, opposition and supination and pronation of elbow was also assessed. Every minute after injection of study drug sensory and motor block assessment was done for establishment of complete sensory and motor block. We include only patients with complete motor block with grade 2 and sensory block grade 1,2. The block was considered incomplete when any of the segments supplied by median, radial, ulnar and musculocutaneous nerve did not have analgesia even after $40 \mathrm{~min}$ of drug 
injection. The patients were supplemented with intravenous fentanyl $(1 \mu \mathrm{g} / \mathrm{kg})$ and midazolam $(0.02 \mathrm{mg} / \mathrm{kg})$.When more than one nerve remained unaffected, it was considered a failed block. In this case general anesthesia was given intraoperatively. Sedation score was assessed by Ramsay Sedation Score ${ }^{[10]}$ [1 = awake, conscious, no sedation; 2 = calm and compose; 3 = awake on verbal command; $4=$ brisk response to gentle tactile stimulation; $5=$ awake on vigorous shaking; $6=$ unarousable]. Sedation scores were recorded just before the initiation and at predefined time periods during surgery. Total duration of analgesia was taken to be from the administration of the block to time of first request of analgesic drug, or VAS Score $\geq 4$ and at this time study period was over. Visual analog scale is $10 \mathrm{~cm}$ scale in which $10=$ severe pain, $0=$ no pain. Degree of bleeding was assessed by operating surgeon using Boezaart's grading system for bleeding ${ }^{[11]}$ [grade 1 = cadaveric conditions with minimal suction required, $2=$ minimal bleeding with infrequent suction required, $3=$ brisk bleeding with frequent suction required, $4=$ bleeding covers surgical field after removal of suction before surgical instrument can perform maneuver, $5=$ uncontrolled bleeding]. Patients were monitored for hemodynamic variables such as heart rate, blood pressure, oxygen saturation every $20 \mathrm{~min}$ intraoperatively and every $30 \mathrm{~min}$ postoperatively up to over of study period. Assessment of blood loss was done and fluid was administered as per the loss. All patients were observed for any side effects like nausea, vomiting, pneumothorax, hematoma, local anesthetic toxicity, post block neuropathy in intraand post-operative periods. Onset time of sensory block: Time after injection of study drug to complete loss of sensation as analyzed by pinprick (grade 1,2). Onset time of motor block: The time elapsed from injection of drug to complete motor block (grade 2). Duration of sensory block: The time elapsed between injection of study drug and demand of first dose of rescue analgesia (VAS Score $>4)$. Duration of motor block: Time elapsed between injection of the drug to complete return of motor power (grade 0). Duration of Surgery: It is taken as time from incision to skin closure.

\section{Sample size and statistical analysis}

Sample size was based on previous studies ${ }^{[12,13]}$. Estimated sample size for two sample comparison of means test with assumption: alpha $=0.05$ (twosided), power $=0.90$; to get the difference of 167 $\min (289 \pm 62 \mathrm{~min}, 456 \pm 97 \mathrm{~min})$ for duration of analgesia in both groups turned out to be 5 in each group.

Statistical analysis: All the quantitative data are presented as mean and standard deviation and compared using student's t-test. Qualitative data such as sedation score, grade of bleeding are presented as frequency and percentage and analyzed using chi-square test. P-value of $<0.05$ was considered as significant and $p<0.001$ was considered as highly significant.

\section{Results}

The 60 patients who fulfilling the inclusion criteria were randomly assigned to one of the two groups. Demographic characters, duration of surgery and ASA grade was comparable in both the group[Table 1]. There was no significant difference in baseline hemodynamic parameters and mean pulse rate, respiratory rate and $\mathrm{SPO} 2$ in both the group intraoperatively after block was given. There was no significant difference in the values of mean systolic blood pressure between two groups at base line and at various time periods (every $20 \mathrm{~min}$ after block) intraoperatively and every hour in postoperative period up to completion of study period. There was no significant difference between two groups in terms of mean diastolic blood pressure at various time periods. [Figure 1,2]. The onset time of sensory and motor block was slightly faster in RD group as compare to RC group but those was statistically non significant ( $\mathrm{p}$ value $>0.05$ ). Numerical value of sensory blockade on set time was express in (Mean \pm SD), these were $2.63 \pm 0.497$ and $2.60 \pm 0.498$ min respectively in RC and RD group 
and onset time of motor block was 4.33 \pm .479 and 4.166 .379 min in group RC and RD respectively. Duration of sensory blockade and motor block was significantly prolonged in RD group as compare to $\mathrm{RC}$ group, (Mean $\pm \mathrm{SD}$ ) of duration of sensory blockade was 224.066 \pm 27.17 and $488.10 \pm 51.50 \mathrm{~min}$ and Motor blockade duration was (Mean \pm SD) 201.5 \pm 42.82 and 357.10 \pm 30.30 min in RC and RD group respectively and these difference was statistically significant $(\mathrm{p}<0.001)$. This may be because peripheral $\alpha_{2}$ agonist produces analgesia by reducing the release of norepinephrine leading to $\alpha_{2}$ receptor independent inhibitory effect onnerve fiber action potentials. $\alpha_{2} / \alpha_{1}$ selectivity of dexmedetomidine is 8 times more than clonidine. [Table 2] Duration of analgesia was also high in RD group as compare to $\mathrm{RC}$ group ( $\mathrm{p}$ value $<0.001$ ) and intraoperative sedation score was high in RD group as compare to $\mathrm{RC}$ group and bleeding during surgery was comparatively low in RD group. [Table2] In, general dexmedetomidine is 8 to 10 times more selective towards@2-AR than clonidine ${ }^{[14]}$ and locus ceruleus of the brain stem is the principal site for sedative action and spinal cord is for analgesia, both acting through @2-AR. Dexmedetomidine potentiates anesthetic effect of all anesthetic agent irrespective of mode of administration. The complications nausea, vomiting found in Group 1 were $3.33 \%$ and in Group 2 were $13.33 \%$. In present study, no case of Horner's syndrome, phrenic nerve palsy or any other nerve injury was observed. One case in group 1 and 4 cases in group 2 complained of nausea, vomiting after completion of surgery, they became normal soon after administration of injection ondansetron. In our study no case of hypotension, bradycardia, chest pain, dysrhythmia, shivering was noted.

Table 1 Comparison of patient demographic profile between two group

\begin{tabular}{|l|c|c|c|}
\hline Parameters & Group RC(n=30) Mean \pm SD & Group RD(n=30) Mean \pm SD & P value \\
\hline Age(year) & $38.43 \pm 7.07$ & $40.5 \pm 8.80$ & 0.32 \\
\hline Weight(kg) & $61 \pm 7.3$ & $61.1 \pm 8.065$ & 0.96 \\
\hline ASA grade I/II & $1.13 \pm 0.33$ & $1.2 \pm 0.40$ & 0.463 \\
\hline Duration of SX(Minute) & $106 \pm 14.40$ & $101.26 \pm 7.60$ & 0.118 \\
\hline Gender M/F & $16 / 14$ & $18 / 12$ & \\
\hline
\end{tabular}

Table 2 Study parameters: between two group

\begin{tabular}{|l|c|c|c|}
\hline (In minute) & RC group (mean \pm SD) & RD group (mean \pm SD) & P value \\
\hline Onset SB & $2.63 \pm 0.497$ & $2.60 \pm 0.498$ & 0.816 \\
\hline Onset MB & $4.33 \pm 0.479$ & $4.166 \pm 0.379$ & 0.147 \\
\hline Duration of SB & $224.066 \pm 27.17$ & $488.1 \pm 51.50$ & $<0.001$ \\
\hline Duration of MB & $201.50 \pm 42.82$ & $357.1 \pm 30.30$ & $<0.001$ \\
\hline Duration of analgesia & $284.86 \pm 49.38$ & $515.73 \pm 37.95$ & $<0.001$ \\
\hline Sedation score & $2.7 \pm 0.65$ & $3.8 \pm 0.406$ & $<0.001$ \\
\hline Grade of bleeding & $2.2 \pm 1.030$ & $1.36 \pm 0.490$ & $<0.001$ \\
\hline
\end{tabular}

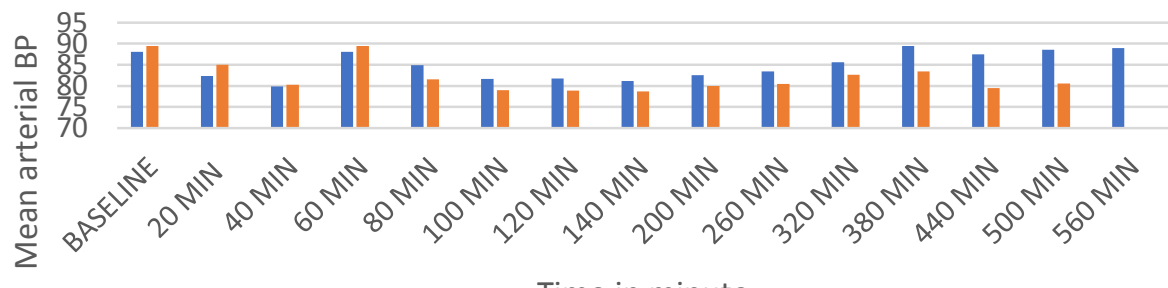

Time in minute

घC GROUP $\quad$ RDGROUP $\quad$ Column1

Figure 1 Variation in Mean arterial blood pressure at various time intervals 


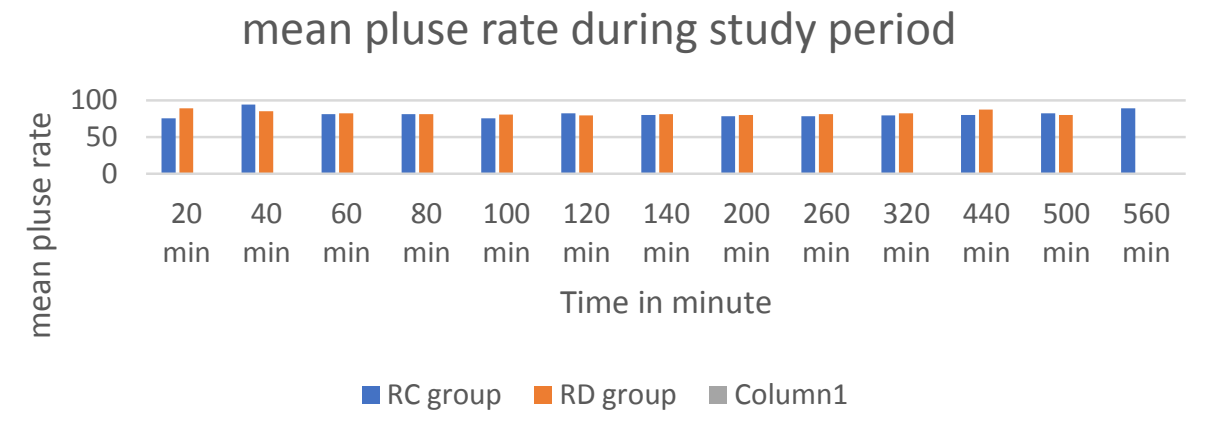

Figure 2 Variation in mean pulse rate during study period at various time intervals

\section{Discussion}

Adjuvants are added to local anesthetics to improve quality of anesthesia and analgesia, and onset time of block, duration of block, decrease postoperative analgesic requirement and systemic side effects by decreasing local anesthetic dose requirement. The role of alpha -2agonist in the management of postoperative pain is established. $[15,16,17]$ The discovery of $\alpha-2$ adreno receptors on primary afferent terminal (both at peripheral and spinal endings), on neuron in the superficial laminae of the spinal cord and within several brainstem nuclei implicated in analgesia supports the possibility of analgesic action of alpha agonist. In our study paresthesia technique was usedwith classical approach of supraclavicular brachial plexus block and paresthesia was sought before injecting study drug. Two patients in either group did not have any loss of sensation up to $40 \mathrm{~min}$. of injection. The block considered unsuccessful and cases were converted into general anesthesia and later excluded from the study. Two patients in group RC had incomplete/partial block but not in the required surgical field and supplement with midazolam and injection diclofenac, they were included in the study. The success rate of blind technique of supraclavicular brachial plexus block (SCB) was $93.33 \%$ in our study and we compared the addition of clonidine (Group RC, $1 \mu \mathrm{g} / \mathrm{kg}, 1 \mathrm{ml}$ ) and dexmedetomidine (Group RD, $1 \mu \mathrm{g} / \mathrm{kg}, 1 \mathrm{ml}$ ) to ropivacaine $0.375 \%$ (39ml) in $(\mathrm{SCB})$. The result of our study showed that the both groups were comparable in demographic profile, ASA grade, duration of surgery and type of surgery but onset time of sensory and motor block both were slightly faster in RD group compare to RC group and statically not significant, duration of sensory and motor block and duration of analgesia were prolonged in RD Group as compare to RC group. Our study supported by Singh and Aggarwal ${ }^{[18]}$, their study results was in favour of addition of clonidine as an adjuvant to bupivacaine in upper extremities block effectively prolong sensory and motor block duration and quality of block also. Esmaoglu A et $a l^{[19]}$ study results was also in favour of addition dexmedetomidine to levobupivacaine for brachial plexus block effectively prolong the duration of motor and sensory block and quality of block also. Above both study suggested that clonidine and dexmedetomidine both increase quality of brachial plexus block. Other study also support our study that clonidine and dexmedetomidine both are central acting alpha 2 agonist when added to local anesthetic agents as an adjuvant in upper extremity block effectively prolong the duration of sensory and motor block and postoperative analgesia with minimum systemic side effects and with better quality of block than control group. ${ }^{[12,20,21]}$. In our study we also noted the sedation score and grade of bleeding intraoperatively. In our knowledge till date there is no study in which both the separameter were recorded in supraclavicular block. We have noted that sedation score was good in RD group as compare to $\mathrm{RC}$ group and bleeding was also minimum in RD group. Mechanism of sedation and analgesia properties with dexmedetomidine is because of stimulation of $\alpha-2$ adrenoceptors located in the locus ceruleus, and dexmedetomidine is more 
selective for $\alpha$-2 adrenoceptors specially for $\alpha-2$ A adrenoceptor subtype than clonidine ${ }^{[22]}$. In our study we found high sedation score in dexmedetomidine group at the time of incision. Intravenous and oral use of $\alpha-2$ adrenoceptor decrease intraoperative bleeding ${ }^{[23,24]}$. Other study conducted by Seema $\mathrm{S}$ et al. in ear surgery, observed that dexmedetomidine is more effective compare to clonidine in view of duration of postoperative analgesia and sedation score, with no difference in terms of onset of analgesia, grade of bleeding and hemodynamic parameters. ${ }^{[25]}$ So by observing results of previous study and our study also we conclude that alpha -2 receptor agonists are good adjuvant when used with local anesthetic in regional anesthesia.

\section{Conclusion}

Dexmedetomidine is a better and cost-effective adjuvant added to ropivacaine asit prolong the duration of sensory and motor block and duration of analgesia and with higher degree of sedation and minimum bleeding in surgical fields as compared to clonidine.

\section{References}

1. http:www.nysora.com/techniques/nervestimulator-and-surface-based-ratechniques/upper-extremitya/index.1.html.

2. Sahu D,Sahu A. Lateral approach for supraclavicular brachial plexus block. Indian J Anaesth.2015;54:215-8.

3. Rettig HC, Gielen MJ, Boersma E, Klein J. A comparison of vertical infraclavicular and axillary approaches for brachial plexus anesthesia. Acta Anaesthesiol Scand.2005;49:1501-8.

4. Ertuz Z, Yegin A, Ertem S, Sahin N, Hadimioglu N,Dosemeci L.et al. Comparison of two different technique for brachial plexus block:-Infraclavicular vs axillary technique. Acta Anaesthesiol Scand.2005;49:1035-9.
5. Stiles P, Prielipp. (springs 2009). Anesthesia patients safety foundation.2013:24;(1)

6. Kuthiala G, Chaudhary G. Ropivacaine: A review of its pharmacology and clinical use. Indian J Anaesth 2011;55: 104-10.

7. 7.Bajwa SJ, Bajwa SK, Kaur J, Singh G, Arora V, Gupta S, etal. Dexmedetomidine and clonidine in epidural anaesthesia: A comparative evaluation. Indian J Anaesth 2011;55:116-21

8. Murphy DB, McCartney CJ, Chan VW. Novel analgesic adjuncts for brachial plexus block: A systematic review. Anesth Analg 2000; 90:1122-8.]

9. Bromage PR. Epidural Analgesia. Philadelphia: WB Saunders; 1978: 144

10. Ramsay MA, Savege TM, Simpson BR, Goodwin R. Controlled sedation with alphaxolone-alphadolone. Br Med J. 1974 Jun 22;2(5920):656-9

11. Boezaart AP, van der Merwee J, Coetzee A. Comparison of sodium nitroprusside and esmolol induced controlled hypotension for functional endoscopic sinus surgery. Can J Anaesth. 1995 May; 42:373-376.

12. Swami SS, Keniya VM, Ladi SD, Rao R. Comparison of dexmedetomidine and clonidine (a2 agonist drugs) as an adjuvant to local anaesthesia in supraclvicular brachial plexus block: A randomized double-blind prospective study. Indian $\mathbf{J}$ Anaesth. 2012 May;56(3):243-9. doi: 10.4103/0019-5049.98767

13. Jinjil K, Bhatnagar V, Swapna P, Tandon U. Comparative evaluation of Alpha two agonists dexmedetomidine with clonidine as adjuvants to $0.25 \%$ ropivacaine for ultrasound guided supraclavicular block: A randomized double-blind prospective study. Int J. of Healthcare and Biomedical Research 2015; 03(3): 20-316.

14. Manpreet K, P.M. Singh. Current role of dexmedetomidine in clinical anesthesia 
and intensive care. Anesth Essay res.2011; $5(2)$

15. Gabriel JS, Gordin V. Alpha 2 agonists in regional anesthesia and analgesia. Curr Opin Anaesthesiol. 2001; 14:751-3.

16. Marhofer D, Kettner SC, Marhofer P, Pils $\mathrm{S}$, Weber $\mathrm{M}$, Zeitlinger $\mathrm{M}$. Dexmedetomidine as an adjuvant to ropivacaine prolongs peripheral nerve block: A volunteer study. Br J Anaesth. 2013; 110:438-42.

17. Yoshitomi T, Kohjitani A, Maeda S, Higuchi H, Shimada M, Miyawaki T. Dexmedetomidine enhances the local anesthetic action of lidocaine via an alpha2A adrenoceptor. Anesth Analg. 2008;107: 96-101.

18. Singh S, Aggarwal A. A randomized controlled double blinded prospective study of the efficacy of clonidine added to bupivacaine as compared with bupivacaine alone used in supraclavicular brachial plexus block for upper limb surgeries Indian J Anaesth 2010; 54:552-557.

19. Esmaoglu A, Yegenoglu F, Akin A, Turk CY. Dexmedetomidine added to levobupivacaine prolongs axillary brachial plexus block. Anesth Analg 2010; 111:1548-1551

20. Qazi Ehsan Ali, Manjunatha, Abdul Quadir. Efficacy of clonidine as an adjuvant to ropivacaine in supraclavicular brachial plexus block: a prospective study. Indian journal of anesthesia. 2014;58 (6):709-713.

21. Tripathi A, Sharma K, Somvanshi M, Samal RL. A comparative study of clonidine and dexmedetomidine as an adjuvant to bupivacaine in supraclavicular block. J Anaesthesiol Clin Phamacol.2016;32(3):344-348.
22. Hunter JC, Fontana DJ, Hedley LR, Jasper JR, Lewis R, Link RE, et al. Assessment of the role of alpha 2-adrenoceptor subtypes in the antinociceptive, sedative and hypothermic action of dexmedetomidine in transgenic mice. $\mathrm{Br} \mathbf{J}$ Pharmacol. 1997 Dec;122 (7):1339-1344.

23. Durmus M, But A K, Dogan Z, Yucel A, Miman M C, Ersoy M O. Effect of dexmedetomidine on bleeding during tympanoplasty or septorhinoplasty. Eur J Anaesthesiol. 2007 May;24(5):447-453.

24. Marchal JM, Gomez-Luque A, MartosCrespo F, Sánchez De La Cuesta F, Martínez-López MC, Delgado-Martinez AD. Clonidine decreases intraoperative bleeding in middle ear microsurgery. Acta Anaesthesiol Scand. 2001;45(5):627-63

25. Seema Shende, Nupur Chakravarty, Shiv Kumar Raghuwanshi, Ramchandra Vinayak Shidhaye. Comparison of dexmedetomidine and clonidine as an adjuvant to lignocaine with adrenaline in infiltration anesthesia for tympanoplasty. Anesthesia pain and intensive care.2016. 